\title{
Framework for an Evidence-Based Physical Activity Intervention: Promoting Healthy Communities
}

\author{
Laura E. Bruno, EdD \\ Department of Health and Exercise Science \\ The College of New Jersey
}

\begin{abstract}
Purpose: Identifying best practices in successful community based intervention programs is critical to improving the health concerns that currently afflict our nation. The purpose of this study was to determine the effectiveness of a community-based physical activity (PA) intervention program in order to share an evidence-based framework that can be used in community settings, including academic communities. The specific objectives of this study were to determine the effectiveness of a community based PA intervention program, specifically noting changes in perceived levels of (a) self-esteem, (b) body size satisfaction, (c) frequency of physical activity and (d) commitment levels the longer a participant engaged in the program. Method: The cross-sectional, quantitative self-report survey design utilized a 29-item web-based questionnaire. A sample of participants $\left(N=383\left(M_{\text {age }}=43\right.\right.$ years; $S D=7$ years; $100 \%$ women $)$ from the Mullica Hill Women's Triathlon Club self-selected to participate.

Results: Independent sample $t$-tests ascertained that the longer a participant engaged in the program, the more her perceived self-esteem improved and the more committed she became to PA. Chi square goodness of fit analyses further demonstrated that a woman's age impacted her level of satisfaction with her body.

Conclusions: Opportunities to participate in a community based intervention program should be extended throughout all communities in an effort to improve holistic well-being. Further, type and duration as well as point of data collection of such programs should be differentiated in future research.
\end{abstract}

Submitted 24 February 2017; accepted 21 March 2017.

Keywords: community based intervention program, academic communities, well-being

Regular physical activity (PA) has many well-known benefits for all individuals, including the intervention of premature disease and disability. The World Health Organization (WHO) has identified physical inactivity as the fourth leading risk factor for global mortality, causing an estimated 3.2 million deaths world-wide (World Health Organization [WHO], 2011). Physical inactivity plays a major role in overweight and obesity concerns: according to the National Health and Nutrition Examination Survey (NHANES), currently more than one-third of U.S. adults are obese (Centers for Disease Control and Intervention [CDC], 2012). The Harvard School of Public Health (2013) has estimated that if the current trend continues, by the year 2030, 50\% of the U.S. population will be obese (Trends section) and the related death toll numbers will continue to grow. Despite this knowledge, fewer than two in ten Americans are meeting the recommended guidelines, defined as 150 minutes of moderate-intensity or 75 minutes of vigorous-intensity (MVPA) aerobic PA for adults, aged 18-64 years old (U.S. Department of Health and Human Services [HHS], 2008).

In addition to the physical benefits of PA, there is evidence (Abbott \& Barber, 2011; DeBate, Gabriel, Zwald, Huberty \& Zhang, 2009) that suggest PA levels associate with psychosocial well-being. Waldron (2009) found that individuals who participated in PA showed improvement in the areas of social competence and physical appearance. Koivula (1999) and Martin \& Hasenblaus (1998) found that individuals who engaged in PA regularly perceived their bodies more positively than those who did not. Variables such as body size satisfaction and self-esteem are important factors that comprise an individual's psychosocial well-being.

The problem remains of how to engage and motivate individuals who lead sedentary lives. There is limited research and discussion of how to build programs that promote a healthy lifestyle approach to health behavior with existing theories of health promotion. The New York Academy of Medicine (NYAM) conducted an extensive literature review to identify the effectiveness of community based intervention programs. Findings demonstrated that 
modest investments in community based interventions ( $\$ 10$ per person) could result in dramatic health care savings (\$16.5 billion in five years; Garcia, Boufford \& Finklestein, 2009). The World Health Organization has recognized that health is not just the absence of illness, disease and injury, but embraces the extension of health to well-being (WHO, 2011). For this reason, community-based intervention programs should consider a more holistic approach when developing a program.

The purpose of this article is to highlight one evidence-based program that has improved the health of the community they serve. These findings are intended to serve as a framework for communities and higher academic institutions, to improve population health and well-being of faculty, staff, students, alumni and the surrounding communities they serve. This article will examine the outcomes and successes of a community based PA intervention program.

The Mullica Hill Women's Triathlon Club (MHWTC), is an all-women's community-based PA intervention program that originated in 2009 in an effort to empower the women of the community to improve their fitness level(s). The MHWTC is open to any woman at least 18 years of age (Mullica Hill Women's Tri Club [MHWTC], 2015a). At the time this study was conducted, 676 women (ages 18-71 years) participated in this community based PA intervention program [MHWTC], 2015b). The club offers the women of the community support and opportunity to improve their health and well-being.

Though membership to the club is limited to women, the club does offer special events that are open to all community members, regardless of gender and age. It is important to note that despite this being a community-based PA intervention program with a cornerstone in the sport of triathlon, upon entering the program, the vast majority of the women are not, and have not, been engaging in regular PA and "many will not have been on a bike since they were 12 years old or laced up their sneakers in years" (MHWTC, 2015b). For this reason, these participants are representative of the at-risk population previously noted. It is through the community workouts and events that many participants challenge themselves to improve their physical fitness levels and some will select to participate in a triathlon within one year.

The intervention, or program, is customizable and will vary from person to person. The MHWTC offers a variety of unique health and fitness opportunities and members can select to participate in as many opportunities as they would like. A sample week of the program offerings can be seen in Table 1.

Table 1

Weekly Overview of the Program/Intervention Opportunities Available to Members

\begin{tabular}{|c|c|c|c|c|c|c|c|}
\hline & Sunday & Monday & Tuesday & Wednesday & Thursday & Friday & Saturday \\
\hline Morning & $\begin{array}{l}\text { Group } \\
\text { Bike Ride } \\
\text { (5 or } 10 \\
\text { miles) }\end{array}$ & $\begin{array}{l}\text { Group } \\
\text { Bike Ride } \\
\text { (5-20 } \\
\text { miles) }\end{array}$ & $\begin{array}{l}\text { Pool Swim } \\
\text { Session }\end{array}$ & $\begin{array}{l}\text { Pool Swim } \\
\text { Session } \\
\text { Yoga }\end{array}$ & $\begin{array}{l}60 \text { minute } \\
\text { walk/run }\end{array}$ & $\begin{array}{l}\text { Pool Swim } \\
\text { Session }\end{array}$ & $\begin{array}{l}\text { Group } \\
\text { Bike Ride } \\
(30+ \\
\text { miles) } \\
\text { Yoga }\end{array}$ \\
\hline Afternoon & $\begin{array}{l}\text { Pool Swim } \\
\text { Session }\end{array}$ & & $\begin{array}{l}\text { Boot } \\
\text { Camp in } \\
\text { the park }\end{array}$ & & $\begin{array}{l}\text { Core } \\
\text { workout } \\
\text { at the } \\
\text { park }\end{array}$ & & \\
\hline Evening & & $\$ 5 / 5 K$ & Lake Swim & $\begin{array}{l}\text { Group Bike } \\
\text { Ride } \\
(5,10,15 \text { or } \\
20 \text { miles })\end{array}$ & $\begin{array}{l}\text { Group } \\
\text { Bike Ride } \\
(15-20 \\
\text { miles) }\end{array}$ & $\begin{array}{l}\text { Pool Swim } \\
\text { Session }\end{array}$ & \\
\hline
\end{tabular}


Health and fitness opportunities are available throughout the week during a variety of times to meet the unique needs of all members. In addition to the weekly PA opportunities, there are social and educational events as well. Tour de Safety and Bike Rodeo is a one-day event that promotes cycling safety and educational information about how to safely navigate the roads. Tripalooza is an event that educates on the sport of triathlon and brings a variety of vendors together to assist new members with bike and helmet fittings, swim clinics and specialists to help with sport technique. There are also social events such as Newbie Night, Speed Meeting Event and an annual ski trip that bring members together to socialize and meet new people.

The study outlined below sought to identify if psychosocial and physical gains succeeding extended participation in the program. The four specific objectives of the study were to determine if there was a statistically significant association between the perceived levels of (a) self-esteem, (b) body size satisfaction, (c) frequency of PA and (d) commitment to PA among those who participated in the program for two or more years and compare results to those who were new to the program or participated less than two years. The two year mark was selected as it represented the half-way point from the inception of the club. This allowed the researcher to see if changes were associated with participation over time (duration).

\section{METHODS}

\section{Procedures}

For this study, participants responded to a battery of four scales. The Institutional Review Board (IRB) at the author's University approved this study. Participants were briefed on the study at the annual kick-off meeting. An explanatory email with the survey questionnaire link was then sent to all eligible club members. Informed consent was obtained from participants upon voluntary completion of the survey questionnaire. The survey questionnaire instrumentation used in this study was created with previously established, reliable and valid tools. The scales consisted of the Rosenberg Self-Esteem Scale, the Figure Rating Scale (FRS), the Commitment to Physical Activity Scale (CPAS) and one single question from the 2005 Youth Risk Behavior Survey (YRBS). The data were then compiled, processed, and statistically analyzed. An alpha level of .05 was set for all statistical tests.

\section{Participants}

Participants self-selected to join the MHWTC. All eligible members of the club were invited to participate in this study. Of the 676 members, (response $=57 \%$ eligible participants), 383 ( $M_{\text {age }}=43$ years; $S D=7$ years; $100 \%$ women) completed the questionnaires in their entirety and were included in the analyses. The vast majority of participants, $98 \%(n=371)$ reported their race as white. Forty-six percent of participants reported having a bachelor's degree and $41 \%$ reported completing graduate school. Descriptive statistics for all demographic variables are presented in Table 2. 
Table 2

Descriptive Statistics for Demographic Variables of MHWTC Participants

\begin{tabular}{|c|c|c|}
\hline Characteristic & Frequency & Value $\%$ \\
\hline Participants (N) & 383 & $100 \%$ \\
\hline \multicolumn{3}{|l|}{ Gender } \\
\hline Women & 383 & $100 \%$ \\
\hline Men & 0 & \\
\hline \multicolumn{3}{|l|}{ Ethnicity } \\
\hline White & 371 & $97 \%$ \\
\hline American Indian or Alaskan Native & 1 & $<1 \%$ \\
\hline Asian & 4 & $1 \%$ \\
\hline From multiple races & 4 & $1 \%$ \\
\hline Declined to answer & 3 & $<1 \%$ \\
\hline \multicolumn{3}{|l|}{ Age } \\
\hline 18 to 24 years & 3 & $<1 \%$ \\
\hline 25 to 34 years & 50 & $13 \%$ \\
\hline 35 to 44 years & 179 & $47 \%$ \\
\hline 45 to 54 years & 129 & $38 \%$ \\
\hline 55 to 64 years & 15 & $4 \%$ \\
\hline 65 to 74 years & 7 & $2 \%$ \\
\hline \multicolumn{3}{|l|}{ Education Background } \\
\hline Graduated from high school & 46 & $12 \%$ \\
\hline Graduated from college & 176 & $46 \%$ \\
\hline Completed graduate school & 158 & $41 \%$ \\
\hline Declined to answer & 3 & $<1 \%$ \\
\hline
\end{tabular}

This community-based PA intervention program is established in Mullica Hill, New Jersey. Mullica Hill is part of Harrison Township which is located in central Gloucester County. Harrison Township is approximately 19.84 square miles with a population of 13,874 people (Harrison Township, 2009). According to the U.S. Census Bureau (2014), "as of 2008 - 2012, the median family income was $\$ 53,020$ and the median housing value is $\$ 334,600$ ” (People QuickFacts section) and " $58 \%$ of the population report as white alone, 2.2\% black or African American, 16.3\% Asian alone, and $44.2 \%$ Hispanic or Latino" (U.S. Census Bureau, 2014). Ninety-four percent $(n=639)$ of participants in the club were from Gloucester County. Thirty percent $(n=202)$ of members reported a Mullica Hill mailing address. Less than 6 percent $(n=37)$ of members were from nearby states including Delaware, Pennsylvania, Maryland, and Massachusetts. 


\section{Measures}

Perceived Self-Esteem. Perceived levels of self-esteem were assessed utilizing the Rosenberg Self-Esteem Scale (Rosenberg, 1965). Morris Rosenberg originally designed this four point scale, ten item questionnaire in 1965. The original scale is a widely used self-report instrument for evaluating individual self-esteem. Scores on the original scale showed adequate internal $(\alpha>$.77) and test-retest (correlation coefficient $>$.88) reliability (Rosenberg, 1965). Participants responded to ten questions, utilizing a four-point scale. Each question related directly to one's perceived self-worth. Possible responses ranged from strongly agree to strongly disagree. Positively phrased questions were assigned the following values: (3) strongly agree, (2) agree, (1) disagree, and (0) strongly disagree. Negatively phrased questions were reverse coded and assigned the following values: (0) strongly agree, (1) agree, (2) disagree and (3) strongly disagree. Thirty was the highest score possible. Each participant earned a mean self-esteem score. A higher score yielded a greater self-esteem mean.

Perceived Body Size Satisfaction. The Figure Rating Scale (FRS) was designed by Stunkard, Sorenson, and Schulsinger (1983). It has established adequate internal consistency (Cronbach's alpha $=0.90)$. The silhouettes are representative of a personal body image assessment via body size satisfaction or dissatisfaction. The scale consists of nine schematic silhouettes ranging from thin to obese. The scale requires participants to first self-select (a) the silhouette that best reflects their current body size and (b) then select the figure that best represents their ideal body size. Participants were then placed in one of three categories: those who were satisfied with their current body size, those who would like to be thinner than their current body size and those who would like to be larger than their current body size.

Physical Activity Frequency. To assess the PA frequency of participants, a single question mirroring a valid and reliable question from the CDC's (2013) Youth Risk Behavior Surveillance (YRBS) asked participants to indicate how many of the past seven days they participated in MVPA (moderate to vigorous physical activity) for at least 20 minutes.

\section{Commitment to Physical Activity.}

The Commitment to Physical Activity Scale (CPAS) was used to assess PA commitment levels. This scale was modified by Corbin, Nielson, Borsdorf \& Laurie (2007) from the Commitment to Running (CR) Scale by substituting the words "physical activity" for "running." Both test-retest and split halves reliability indicated the CPAS had good internal consistency (Cronbach's alpha $=.99$ ) and the average inter-item correlation coefficient was 0.377. This twelve question test consisted of a four point scale assessment. Possible responses ranged from "strongly agree" to "strongly disagree." Positively phrased questions were assigned the following values: (3) strongly agree, (2) agree, (1) disagree and (0) strongly disagree. Negatively phrased questions were assigned the following values: (0) strongly agree, (1) agree, (2) disagree and (3) strongly disagree. Thirty-six was the highest score possible.

\section{Data Analyses}

Measures of central tendency and dispersion, as well as frequencies and percentages were analyzed to provide a summary of the results. Data was examined for normality and outliers, and computed descriptive statistics for each variable stratified by participation in years. For the main analyses, the researcher conducted independent samples t- tests, ANOVA and Chi-square goodness of fit analyses where appropriate. The intent of this study was to better understand if participation in a community based PA intervention program produced greater changes over time. With this information, inferences could be made regarding the effectiveness of such programs and serve as a framework for other communities to use. To address program duration, membership data was re-coded into two groups: (1) those that were new to the program, or participated less than two years, and (2) those who participated two to five years. The two year mark was identified as significant since it was representative of the membership half way point. This allowed the study to focus on two independent sample means. 


\section{RESULTS}

Descriptive statistics for all study variables stratified by membership in years (or level of participation) are presented in Table 3.

Table 3

Sample Size and Means for the MHWTC Descriptive Variables Stratified by Membership in Years

Membership Less Than 2 Years

Means (SD)

\begin{tabular}{lr} 
Variables & $n$ \\
\hline & 163
\end{tabular}

Self-Esteem

PA Frequency

PA Commit-

ment

Body Size Satis-

faction:

Satisfied

Smaller

Larger

31

$19 \%$

$81 \%$

$0 \%$

$*$ Significant association at $p<.05$

Means differed slightly between the two groups for perceived self-esteem, body size satisfaction and PA frequency. The greatest mean difference between the two groups was noted in the variable, PA commitment, respectively. 


\section{Associations between Participation and Perceived Levels of Self-Esteem}

The Rosenberg Self-Esteem Scale mean totals differed slightly between those who participated less than two years ( $n$ $=163, M=21.03, S D=4.79)$, with those who participated two or more years $(n=220, M=22.34, S D=4.48)$. An independent-samples $t$-test ascertained there was a statistically significantly difference in perceived level(s) of selfesteem the longer a participant engaged $t(381)=2.75, p=.006$. Additional chi-square goodness of fit tests determined there was also a significant association between perceived level(s) of self-esteem and education background/level $X$ ${ }^{2}(38)=59.231, p=.015$. Based on the results, an item analysis was conducted on each of the ten Rosenberg SelfEsteem Scale statements. Chi-square analyses revealed there was a statistically significant association between those who were new or participated less than two years when compared with those who participated in the club two or more years on four of the ten statements: "On the whole, I am satisfied with myself" (84\% and $88 \%$ respectively); "I feel that I am a person of worth, at least on an equal plane with others (85\% and $96 \%$ respectively); "All in all, I am inclined to feel that I am a failure" ( $6 \%$ and $2 \%$ respectively); and "I take a positive attitude toward myself" (82\% and $90 \%$ respectively). Cramer's $\mathrm{V}$ indicated a weak-to-moderate association between the two groups for each of the above statements, Phi $(\varphi)=.044-.063$. No other statistically significant associations were observed when perceptions of self-esteem with participant age were compared.

\section{Associations between Participation and Perceived Body Size Satisfaction}

The Figure Rating Scale (FRS) mean totals were quite similar between those who participated less than two years $(n=163, M=.81, S D=.394)$, with those who participated two or more years $(n=220, M=.81$, $S D=.416)$. An independent samples $t$-test was conducted between participation in years and perceived level(s) of body size satisfaction. Results concluded that a statistically significant association between these two variables did not exist, $t(381)=.552, p=$.986. Additional chi-square tests between age and perceived level(s) of body size satisfaction ascertained that a statistically significant association between the two variables did exist, $X^{2}(10)=19.231, p=.037$. Phi $(\varphi)$ measured the strength between these two variables and concluded a moderate-strong association between age and perceived levels of body size satisfaction, $\varphi=0.216, p=.057$. $<$ See Figure 1>. 


\section{Perceived Body Size Satisfaction}

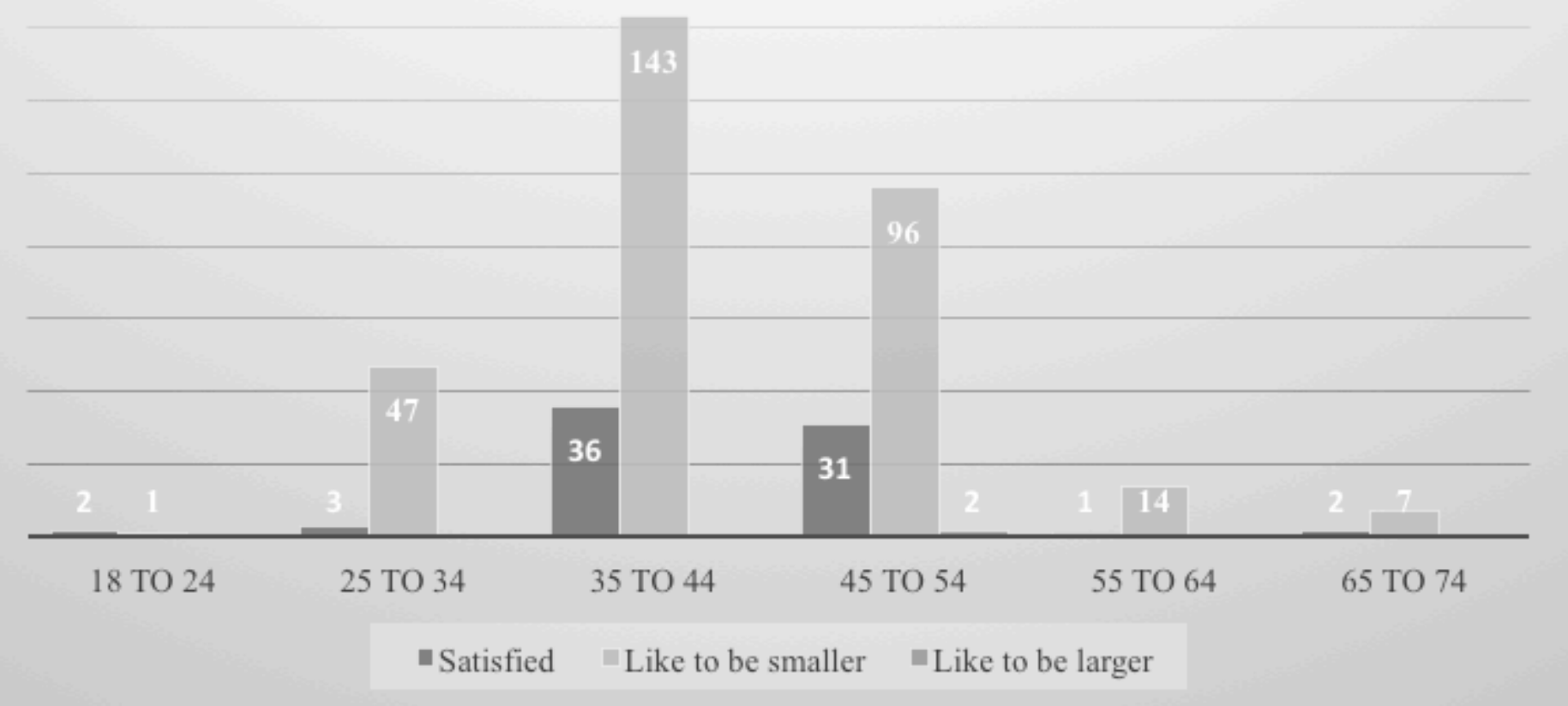

Figure 1. Comparison between perceived body size satisfactions among the women of the MHWTC stratified by participant age. Results significant at $p<.05$.

No other statistically significant differences were observed when comparing perception of body size satisfaction with educational background and year-by-year membership.

\section{Associations between Participation and Physical Activity Frequency}

Those participants who were members more than two years reported slightly higher mean participation scores $(n=$ 220, $M=3.89, S D=1.62)$ than their newer counterparts $(n=163, M=3.58, S D=1.70)$. An independent sample $t$-test concluded that these differences were not statistically significant, $t(381)=-1.773, p=.08$. No other statistically significant associations were observed when perceived PA commitment levels were compared with participant age and educational background.

\section{Associations between Membership and Physical Activity Commitment}

The Commitment to Physical Activity Scale mean totals differed slightly between those who participated less than two years $(n=163, M=24.63, S D=5.72)$, and those who participated two or more years $(n=220, M=27.42, S D$ $=5.17)$. An independent samples $t$-test was conducted between participation in years and perceived level(s) of body size satisfaction. Results concluded a statistically significant association between these two variables, $t(381)=-4.992$, $p=.00$. Additionally, an item analysis was conducted on the Commitment to Physical Activity Scale statements. Chisquare goodness of fit analyses concluded there was a statistically significant association between those who were new or participated less than two years when compared with those who participated two or more years on eleven of the twelve statements $<$ See Figure 2>. 


\section{Comittment to Physical Activity}

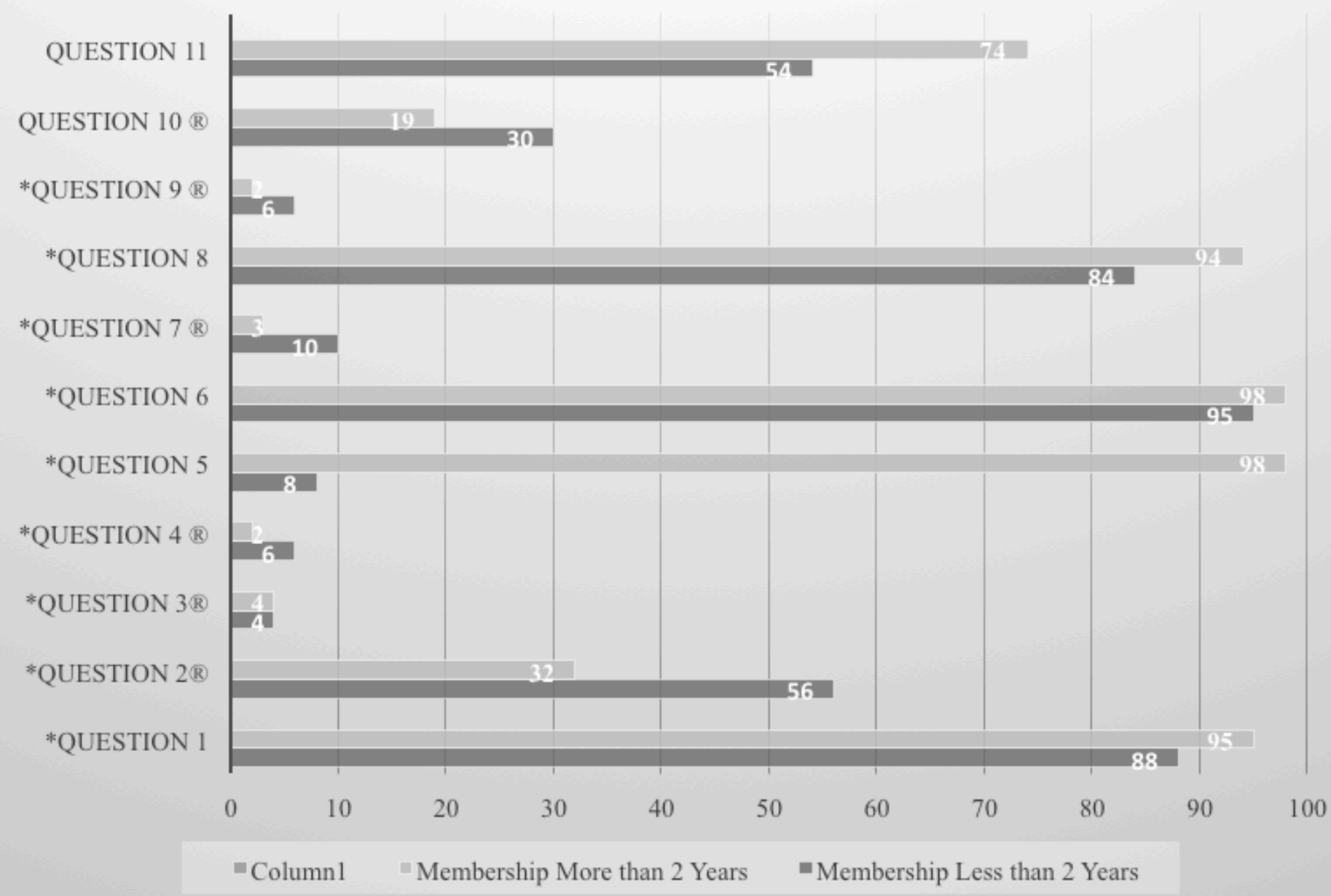

Figure 2. Comparison between PA commitment levels among the women of the MHWTC stratified by participant age. $*$ Results significant at $p<.05$. ${ }^{\circledR}$ Indicates questions that are reverse coded.

This overall trend indicates a positive association with the above statements for those who participated in the program more than two years. Phi and/or Cramer's V indicated a strong association between the two variables for each of the above statements, Phi $(\phi)=.000-.030$. Only one of the twelve statements on the CPAS did not produce a statistically significant association, "To miss a day of physical activity is sheer relief" (15\% and $8 \%$ respectively), $X$ ${ }^{2}(3)=7.187, p=.066$. No other statistically significant associations were observed when perceived PA commitment levels were compared with participant age and educational background. 


\section{DISCUSSION}

The need for the development of community based intervention programs is evident. Universal knowledge suggests that being physically active is one of the most important steps a person can take to improve their overall health (U.S. Department of Health \& Human Services, 2008). Furthermore, sport and exercise literature note that PA not only benefits physical well-being, but also psychosocial well-being (Boyd \& Hrycaiko, 1997). For these reasons, community based intervention programs should include components that encompass a holistic approach to wellness. Evidence is clear that intervention is the key to better health [NYAM] Garcia, Boufford \& Finklestein, 2009). Many national initiatives support the concept of community involvement in physical activity promotion and while it appears to be a simple concept; the reality is that it remains one of the least frequently implemented components of a PA-program to date.

Greater knowledge is needed regarding the benefits and framework for successful community-based intervention programs. This evidence-based study evaluated the effectiveness of a well-implemented community-based PA intervention program. Participant gains, as outlined above included greater levels of perceived self-esteem and a deeper commitment to physical activity; both of which relate to improved holistic well-being. This community based PA intervention program has proven to be effective in what it set out to do. Communities and higher academic institutions should replicate a similar framework to improve population health and well-being of faculty, staff, students, alumni and the surrounding communities they serve.

\section{Study Limitations and Strengths}

There are limitations to this study that should be considered when interpreting the results. One of the limitations of a cross-sectional design is the time dimension; participants in this study were issued the survey questionnaire one time, at the start of the 2014 season. Future research may consider issuing the questionnaire at a later point in the season after training is underway. Next, participants self-selected to join the program. Self-selected participation may indicate a greater level of motivation to be physically active. Since data collection was based on electronic questionnaire surveys through email communication, it is possible all eligible members did not receive the online survey questionnaire link. Since participation was completely anonymous, it is possible that a person other than the intended participant may have completed the questionnaire, or a participant may have completed the survey questionnaire more than once, thus skewing the results. Despite these limitations, this investigation builds on previous findings by examining both the physical and psychosocial associations of participation in a community based PA intervention program. This study further provided a framework for communities and organizations to model when implementing a community-based intervention program.

\section{Implications for Future Research}

The findings from this study provide valuable information about community-based intervention programs. Specifically, the physical and psychosocial gains revealed indicate community intervention program efforts are impactful. This evidence-based study should serve as confirmation that if properly implemented, utilizing a similar framework, community intervention programs are beneficial to all those involved. Future research might consider comparing the results and framework of a different community based intervention program. Future research may also investigate these variables at a later point in time (once regular training is underway) as this study was completed in the preliminary phase of the season. Lastly, this study should be replicated to a different sample group, as this participant population is not representative of the general population within the nation; future studies should replicate the study with a demographically diverse population. 


\section{REFERENCES}

Abbott, B. D., \& Barber, B. L. (2011). Differences in functional and aesthetic body image between sedentary girls and girls involved in sports and physical activity: Does sport type make a difference? Psychology of Sport and Exercise, 12(3), 333342. https://doi.org/10.1016/j.psychsport.2010.10.005

Boyd, K. R., \& Hrycaiko, D. W. (1997). The effect of a physical activity intervention package on the self-esteem of preadolescent and adolescent females abstract. Adolescence, 32(127), 693-708.

Centers for Disease Control and Prevention (2012). 2009-2010 National health and nutrition examination survey (NHANES). Retrieved from http://www.cdc.gov/nchs/nhanes.htm

Centers for Disease Control and Prevention (2013). Youth Risk Behavior Surveillance System (YRBSS). Mortality and Morbidity Weekly Report, 62(1), 1-22. Retrieved from http://www.cdc.gov/healthyyouth/yrbs/index.htm

Corbin, C., Nielson, A., Borsdorf, L., \& Laurie, D. (2007). Commitment to physical activity. International Journal Sport Psychology, $18,215-222$

DeBate, R. D., Gabriel, K. P., Zwald, M., Huberty, J., \& Zhang, Y. (2009). Changes in psychosocial factors and physical activity frequency among third-to-eighth-grade girls who participated in a developmentally focused youth sport program: A preliminary study. Journal of School Health, 79(10), 474-484.

https://doi.org/10.1111/j.1746-1561.2009.00437.x

Garcia, A.C., Boufford, J., \& Finkelstein, R. (2009). New York Academy of Medicine (NYAM). A Compendium of Proven Community based Intervention Programs. 10.

Harrison Township, Gloucester County, N.J. (2009). Welcome to Harrison Township, NJ. Retrieved from http://harrisontwp.us/ about-harrison-township/who-is-harrison-twp/

Harvard School of Public Health (2013). Obesity trends in America. Retrieved from http://www.hsph.harvard.edu/obesityintervention-source/us-obesity-trends-map/

Koivula, N. (1999). Sport participation: Differences in motivation and actual participation due to gender typing. Journal of Sport Behavior, 22, 360-381.

Martin, K., \& Hausenblaus, H., (1998). Psychological commitment to exercise and eating disorder symptomology among female aerobics instructors. Sport Psychology, 12, 180-190. https://doi.org/10.1123/tsp.12.2.180

Mullica Hill Women's Tri Club (2013a). Why join? Retrieved from http://mullicahilltriclub.com/index.php/join/why-join/

Mullica Hill Women's Tri Club (2013b). About our club. Retrieved from http://mullicahilltriclub.com

Rosenberg, M. (1965). Society and the adolescent self-image. Princeton, NJ: Princeton University Press. https://doi.org/10.1515/9781400876136

Stunkard, A. J., Sorensen, T., \& Schulsinger, F. (1983). Use of the Danish Adoption Register for the study of obesity and thinness. Research Publications Association for Research in Nervous \& Mental Disease, 60, 115-120. Retrieved from http://www.researchgate.net/publication/16374544_Use_of_the_Danish_Adoption_Register_for_the_study_of_ obesity_and_thinness

U.S. Census Bureau (2014). State and County QuickFacts, Harrison (town), New Jersey. Retrieved from https://www.census.gov/quickfacts/table/PST045216/3401530180,00

U.S. Department of Health \& Human Services, Office of Disease Intervention \& Health Promotion (2008). Physical activity guidelines for Americans. Retrieved from http:/ /www.health.gov/paguidelines

Waldron, J. J. (2009). Development of life skills and involvement in the Girls on Track program.

Women in Sport and Physical Activity Journal, 18, 60-74. https://doi.org/10.1123/wspaj.18.2.60

World Health Organization (WHO; 2011). New physical activity recommendations for reducing disease and prevent deaths. Retrieved from www.who.int/chp/media/news/releases/2011_2_physicalactivity/en/index.html 
Please address author correspondence to

Laura E. Bruno, EdD

Department of Health and Exercise Science

The College of New Jersey

Ewing, NJ 08628

Tel: 609-771-2195

Fax 609-637-5153

brunol@tcnj.edu

\section{AUTHOR NOTE}

This manuscript is based on data collected from a doctoral dissertation. The author wishes to acknowledge Lewis Atkinson III and Julie Lanzillo, Wilmington University, Peter Rattigan, Rowan University and Kathy Shelton for their guidance and assistance with the dissertation process and manuscript preparation. The author also wishes to acknowledge Colleen Fossett and the members of the Mullica Hill Women's Tri Club for their assistance and participation in the study. 